\section{New charity will educate on dental}

\section{tracama}

A new charity is due to launch this November to help educate the public and dental professionals in the management of dental trauma.

Dental Trauma UK has been set up to help improve the care and treatment options for patients following traumatic dental injuries

According to the charity, too many people are losing teeth unnecessarily after dental trauma, mainly because they are unaware of basic preventive steps to undertake in the aftermath of dental injury, such as re-implanting it, or putting it in milk and seeing a dentist urgently.

Miss Serpil Djemal, Consultant in Restorative Dentistry at King's College Hospital, London, and founder of Dental Trauma UK, said: 'More teeth can be saved if we can better educate the public about what to do in the immediate aftermath of dental trauma injury. We are really excited about getting started'.

Dental Trauma UK will work to raise awareness among the general public, but also those who are often 'first on the scene' when dental injury occurs - including teachers, youth workers, paramedics, police, and sports coaches.

The charity will also collect research information on the number, causes and types of traumatic dental injuries throughout the UK as well as provide specialist support and advice to dental professionals to disseminate best practice in this area.

\section{http://www.dentaltrauma.co.uk/}

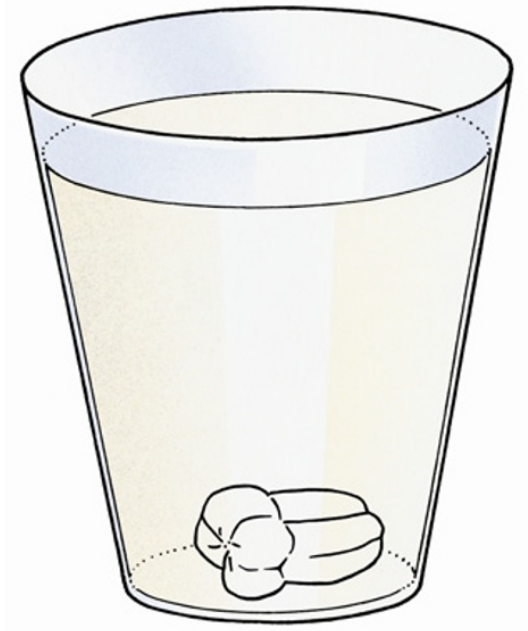

\section{COMMUNICATION TOOL IMPROVES COOPERATION IN CHILDREN WITH AUTISM}

A new communication tool has been created for dental professionals who work with children and young people with autism spectrum disorders or learning difficulties. Sheffield Salaried Primary Dental Care Service worked with children, parents and software company Widgit to develop a four-page tool which uses graphic symbols alongside text to aid communication and understanding.

An evaluation of the communication tool in association with the University of Sheffield, published in the Journal of Disability

and Oral Health, showed that children's

cooperation with treatment improved. ${ }^{1}$ Some

children coped with treatment that they had

previously found impossible; others started to

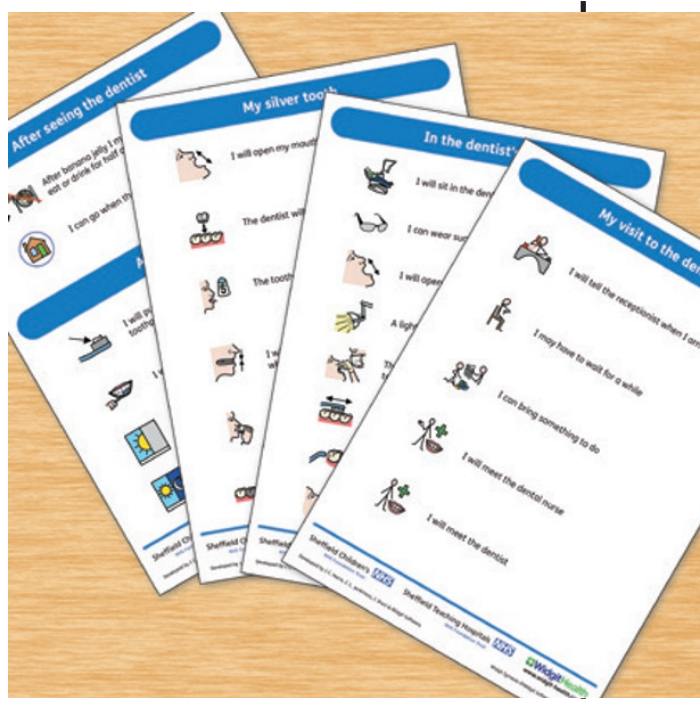

communicate verbally with the dental team

when they had never spoken in the dental surgery before. Use of the tool also improved the clinicians' confidence and job satisfaction.

The leaflets can be used to prepare a child in advance of the dental appointment, laminated to use in the surgery or given out to encourage oral care at home. Procedures supported include fluoride varnish application, in accordance with current prevention guidance, and placement of preformed metal crowns using the Hall Technique.

To download and print the leaflets, which are free of charge, visit http://www.widgithealth.com/downloads/dental-procedures.htm. It is also possible to create your own customised materials.

1. Harris J C, Marshman Z, Short J A. Development and qualitative evaluation of a communication tool for children with autism spectrum disorders and other communication difficulties. J Disabil Oral Health 2014; 15: 33-39.

\title{
COULD YOU WRITE AN ARTICLE FOR BDJ TEAM?
}

Would you like to contribute to $B D J$ Team, the online monthly magazine for all dental care professionals (DCPs)? We are keen to hear from you if:

You are involved with research or audit and would like to submit an article for peer review and possible publication

You would like to appear in a 'day in the life' style profile piece

> You have had an exciting career or have an unusual hobby and would like to write about it for BDJ Team

$>$ You are an expert on a core CPD topic and would like to share your knowledge through an original article for $B D J$ Team

You would like to appear in a mini 'FLASH INTERVIEW'

> Your dental practice has been involved in a special event (such as fundraising, oral health education in the community, a practice open day or practice makeover) and you think it would make a good news story.

OR perhaps you have an idea for an article that you would like to see in BDJ Team or a topic not yet covered - or not covered often enough.

We would love to hear from you. Please email the Editor, Kate Quinlan, on bdjteam@ nature.com, call 02078433680 (office hours) or write to BDJ Team, BDJ Editorial, 4-6 Crinan Street, London, N1 9XW. ALL IDEAS AND SUGGESTIONS WELCOME! 